\title{
Deep Brain Stimulation for Obesity: A Review and Future Directions
}

\author{
Douglas A. Formolo1,2, Joana M. Gaspar3,4, Hiago M. Melo1,2, Tuany Eichwald ${ }^{3,4}$, \\ Ramiro Javier Zepeda ${ }^{5}$, Alexandra Latini,3,4 Michael S. Okun ${ }^{6}$ and Roger Walz ${ }^{1,2,6,7,8 *}$ \\ ${ }^{1}$ Center for Applied Neuroscience, University Hospital, Federal University of Santa Catarina, Florianópolis, Brazil, ${ }^{2}$ Graduate \\ Program in Neuroscience, Federal University of Santa Catarina, Florianópolis, Brazil, ${ }^{3}$ Laboratory of Bioenergetics \\ and Oxidative Stress, Department of Biochemistry, Federal University of Santa Catarina, Florianópolis, Brazil, ${ }^{4}$ Graduate \\ Program in Biochemistry, Department of Biochemistry, Federal University of Santa Catarina, Florianópolis, Brazil, \\ ${ }^{5}$ Department of Neuroscience, Faculty of Medicine, Chile University and Health Science Institute, O'Higgins University, \\ Santiago, Chile, ${ }^{6}$ Fixel Institute for Neurological Diseases, Department of Neurology, University of Florida, Gainesville, FL, \\ United States, ${ }^{7}$ Graduate Program in Medical Sciences, Federal University of Santa Catarina, Florianópolis, Brazil, \\ ${ }^{8}$ Department of Internal Medicine, University Hospital, Federal University of Santa Catarina, Florianópolis, Brazil
}

\section{OPEN ACCESS}

Edited by: Sebastian Cerdan Spanish National Research Council (CSIC), Spain

Reviewed by:

Emmanuel N. Pothos, Tufts University School of Medicine,

United States

Adam Olding Hebb,

Colorado Neurological Institute (CNI), United States

*Correspondence: Roger Walz

rogerwalz@hotmail.com

Specialty section: This article was submitted to Neuroenergetics, Nutrition and Brain Health,

a section of the journal

Frontiers in Neuroscience

Received: 16 October 2018

Accepted: 21 March 2019

Published: 18 April 2019

Citation:

Formolo DA, Gaspar JM, Melo HM, Eichwald T, Zepeda RJ, Latini A, Okun MS and Walz R (2019) Deep Brain Stimulation for Obesity: A Review and Future Directions. Front. Neurosci. 13:323. doi: 10.3389/fnins.2019.00323
The global prevalence of obesity has been steadily increasing. Although pharmacotherapy and bariatric surgeries can be useful adjuvants in the treatment of morbid obesity, they may lose long-term effectiveness. Obesity result largely from unbalanced energy homeostasis. Palatable and densely caloric foods may affect the brain overlapped circuits involved with homeostatic hypothalamus and hedonic feeding. Deep brain stimulation (DBS) consists of delivering electrical impulses to specific brain targets to modulate a disturbed neuronal network. In selected patients, DBS has been shown to be safe and effective for movement disorders. We review all the cases reports and series of patients treated with DBS for obesity using a PubMed search and will address the following obesity-related issues: (i) the hypothalamic regulation of homeostatic feeding; (ii) the reward mesolimbic circuit and hedonic feeding; (iii) basic concepts of DBS as well as the rationale for obesity treatment; (iv) perspectives and challenges in obesity DBS. The small number of cases provides preliminary evidence for the safety and the tolerability of a potential DBS approach. The ventromedial $(n=2)$ and lateral $(n=8)$ hypothalamic nuclei targets have shown mixed and disappointing outcomes. Although nucleus accumbens $(n=7)$ targets were more encouraging for the outcomes of body weight reduction and behavioral control for eating, there was one suicide reported after 27 months of follow-up. The authors did not attribute the suicide to DBS therapy. The identification of optimal brain targets, appropriate programming strategies and the development of novel technologies will be important as next steps to move DBS closer to a clinical application. The identification of electrical control signals may provide an opportunity for closed-loop adaptive DBS systems to address obesity. Metabolic and hormonal sensors such as glycemic levels, leptin, and ghrelin levels are candidate control signals for DBS. Focused excitation or alternatively inhibition of regions of the hypothalamus may provide better outcomes compared to non-selective DBS. Utilization of the NA delta oscillation or other physiological markers from one or multiple regions in obesity-related brain network is a promising approach. Experienced multidisciplinary team will be critical to improve the risk-benefit ratio for this approach.

Keywords: obesity, deep brain stimulation, hypothalamus, nucleus accumbens, metabolic disorders, neuroinflammation 


\section{INTRODUCTION}

According to the World Health Organization (WHO), obesity is defined as an abnormal and excessive fat accumulation. The increase in fat mass is a major health problem and is a risk factor for the development of several metabolic complications. Obesity decreases the quality of life and decreases life expectancy. The incidence of obesity has continued to rise rapidly during the last several decades. Similarly, the prevalence of obesity has been rising in most countries worldwide, and its prevalence has doubled in more than seventy countries over the last four decades. It was estimated that in 2015 there were a total of 603.7 million obese adults (body mass index [BMI] $>30 \mathrm{~kg} / \mathrm{m}^{2}$ ) and 107.7 million obese children (defined as a BMI at or above the 95th percentile). Approximately 1.9 billion adults are by definition overweight (BMI $>25 \mathrm{~kg} / \mathrm{m}^{2}$ ) (Gonzalez-Muniesa et al., 2017). The rising prevalence of obesity has been associated with a higher incidence of chronic metabolic disorders including type 2 diabetes. Both diseases share similar features including early cognitive dysfunction and a substantial socio-economic impact (Gaspar et al., 2016; Remor et al., 2018).

The etiology of obesity results from a complex interaction of several factors, including socioeconomic status, genetics, epigenetics, cultural features, and lifestyle. The obesity problem is even more complex with a link to compulsive eating behaviors and to depression (Val-Laillet et al., 2015; Ivezaj et al., 2016). Although no cause-and-effect relationship has been conclusively established, a systematic review revealed that obesity and depression had a significant and bidirectional association. The association with anxiety was modest but potentially important (Rajan and Menon, 2017). Despite its multifactorial etiology, a general consensus has emerged that the majority of obesity cases result from the combination of an increase in food intake along with a decrease in energy expenditure which together results in excessive fat accumulation. In most cases, obesity is a preventable disease and is largely dependent on lifestyle. Living a healthy lifestyle has recently become more of a challenge with elevated levels of stress, reduction of physical activity and the availability of palatable foods that are high in sugar, fat, and calories. The increased availability of an energy-dense diet, high in saturated fat and sugar, has been strongly associated with weight gain and increased adiposity, precipitating a strong change in energy balance not only resulting from a simple increase in energy intake (McClelland et al., 2013).

The palatable and densely caloric foods affect brain circuits involved with the control of energy metabolism in the hypothalamus and those involved with reward and humor perception within the limbic system. In predisposed, individuals this combination may result in overeating patterns and manifest as a "food addiction" or "food abuse." This phenomenon can increase the difficulty in achieving a long-term successful reduction of caloric intake by non-pharmacological and pharmacological approaches. This phenomenon has also increased the challenges of bariatric surgery for individuals with morbid obesity (Stice et al., 2013). Additionally, genetic factors might contribute to vulnerability to weight gain that, in combination with the environment precipitants result in brain network changes. This may reinforce the desire for food intake even if this desire is incongruent with the aspiration to reduce weight (Horstmann, 2017). Neuromodulation for the regulation of homeostatic and hedonic feeding has been suggested as a potential approach.

We review all the cases reports and series of patients treated with DBS for obesity using a PubMed search and will address the following obesity-related issues: (i) the hypothalamic regulation of homeostatic feeding; (ii) the reward mesolimbic circuit and hedonic feeding; (iii) basic concepts of DBS as well as the rationale for obesity treatment; (iv) perspectives and challenges in obesity DBS.

\section{HYPOTHALAMUS, HOMEOSTATIC FEEDING, AND OBESITY}

Homeostatic feeding is necessary for basic metabolic processes and survival (Rossi and Stuber, 2018). Energy homeostasis which is defined as a balance between food intake and energy expenditure is regulated primarily by the hypothalamus. The hypothalamus regulates food intake and energy expenditure but also regulates peripheral glucose and lipid homeostasis as well as metabolism (Morton et al., 2014; Timper and Bruning, 2017).

The discovery of the hypothalamus as a key center for energy homeostasis had its genesis with the studies of Hetherington and Ranson (1940) which revealed that adiposity increased in rats with hypothalamic lesions. Additionally, the discovery of leptin in 1996, by Zhang et al. (1994) opened new pathways for the molecular understanding of the role of the hypothalamus in the regulation of food intake and energy expenditure.

The Figure 1 shows the interconnected hypothalamic nuclei, including the arcuate nucleus (ARC), the paraventricular nucleus $(\mathrm{PVN})$, the ventromedial nucleus (VMN), the dorsomedial nucleus, and the lateral hypothalamic area (LHA) in both the healthy and the obesity state. Due to its privileged anatomical location, ARC is the principal region to receive and to sense afferent signals (nutrients and hormones) from the gut and the brainstem, as well as the region that processes efferent signals capable of modulating both food intake and energy expenditure. Two well-defined neuronal populations within the ARC have been described and each has been characterized by the expression of specific neuropeptides. These neuronal populations have potent effects on energy homeostasis namely, proopiomelanocortin (POMC) and agoutirelated protein/neuropeptide Y (AgRP/NPY) (Morton et al., 2014; Sohn, 2015; Timper and Bruning, 2017). However, more recently it was identified that there was a third neuronal population which expressed tyrosine hydroxylase and had orexigenic characteristics (Zhang and van den Pol, 2016). All of these neuronal populations express high levels of hormone receptors (e.g., insulin, leptin, ghrelin, GLP-1, among others) and these receptors seem to facilitate a response to metabolic signals and to reflect the energy state of the organism as well as to control energy homeostasis (Figure 1A). 


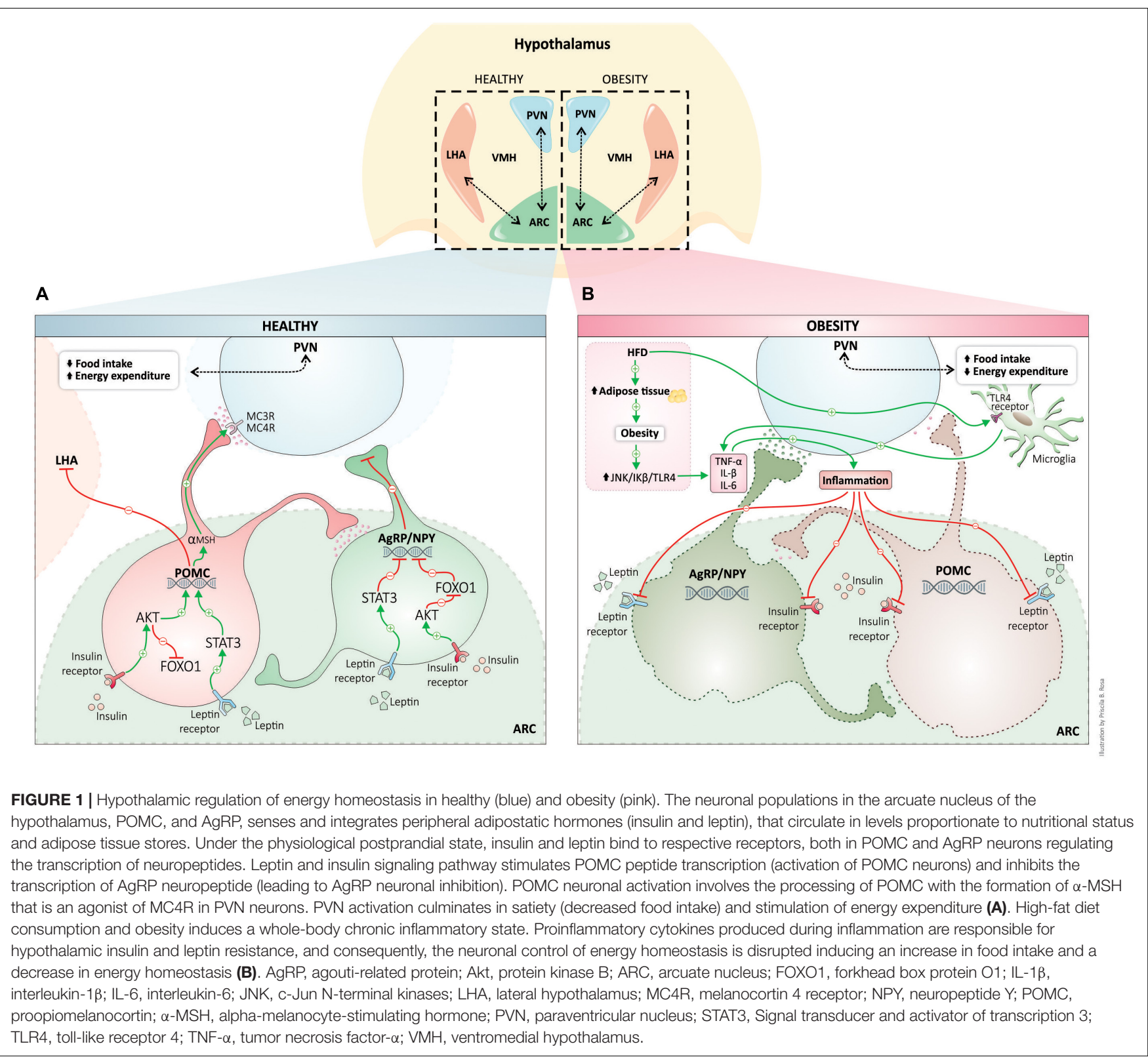

The anorexigenic neurons, the POMC, are activated by adiposity signals, such as leptin, insulin, and some nutrients. The binding of leptin to its receptor induces the phosphorylation of the transcription factor STAT3 and this reaction upregulates POMC expression (Hakansson and Meister, 1998; Lee et al., 2018). Neuronal insulin signaling induces phosphorylation of forkhead box protein O1 (FOXO1), which is also a transcription factor that increases the expression of POMC (Belgardt et al., 2008). POMC is a neuropeptide that is post-translationally processed in several active peptides, including $\alpha$ and $\beta$ melanocyte-stimulating hormone (MSH) and $\beta$-endorphins (Liotta et al., 1980; Wardlaw, 2011). After activation, neuronal projections of POMC neurons activate second-order neurons in the PVN, acting on the melanocortin receptors (MC3R/MC4R) leading to a decrease in food intake and to an activation of energy expenditure. The activation of POMC neurons has been shown to decrease body weight (Cheung et al., 1997; Wardlaw, 2011; Mountjoy, 2015). By contrast, the second population of AgRP/NPY neurons, inhibited by leptin and activated by fasting and ghrelin, has been shown to have a potent orexigenic effect, increasing food intake and decreasing energy expenditure (Wu et al., 2014). Ghrelin is primarily produced by stomach cells under fasting conditions. Ghrelin modulates feeding behavior and metabolism through the ghrelin receptor. The ghrelin receptor is abundantly expressed in the hypothalamus, mainly in AgRP/NPY neurons. AgRPq/NPY neurons are depolarized and activated by ghrelin. Concomitantly, ghrelin hyperpolarizes and inhibits POMC neurons (Kamegai et al., 2000; Al Massadi et al., 2017). In the fed state, AgRP expression is suppressed by leptin. Under fasting conditions (no leptin release) there is an 
increase in AgRP and consequent increases in food behavior and adiposity. Activation of these neuronal populations leads to a release of AgRP, which is an antagonist of the MC4 receptor, and it inhibits PVN neurons. This process blocks the satiety feeling and stimulates feeding behavior through activation of lateral hypothalamic neurons (LHA) (Figure 1A) (Hahn et al., 1998; Luquet et al., 2005; Sohn, 2015).

Obesity is considered by many experts to be a low-grade chronic inflammatory condition. For several years, it was believed that the link between peripheral insulin resistance and obesity was a consequence of several variable factors including feeding patterns, consumption of high-fat diets, sedentary lifestyle and also that obesity occurred from stress. All of these factors are involved in the induction of systemic inflammation which can result in changes in metabolic and endocrine signaling (Hotamisligil, 2017). The expansion of white adipose tissue which occurs during the development of obesity produces proinflammatory cytokines (TNF- $\alpha$, IL-1 $\beta$, and IL-6) through the activation of intracellular serine kinases, such as JNK and IkB kinase. These kinases participate in the induction of insulin resistance (see review, Hotamisligil, 2017). Inflammation is also a hallmark in the brain of rodents under peripheral metabolic dysregulation (Remor et al., 2018), and in the hypothalamus of diet-induced obesity models (De Souza et al., 2005; Wang et al., 2012) (Figure 1B). Besides neuroinflammation, hypothalamic dysregulation induced by high-fat diets can result in an increase in markers of oxidative stress, endoplasmic reticulum stress, autophagy defects and changes in the rate of apoptosis and neuronal regeneration (Cavadas et al., 2016).

Unlike inflammation in peripheral tissues, which develops as a consequence of obesity, hypothalamic inflammatory signaling, microglia activation, and gliosis is observed during the first week of high fat diet consumption. They can also be observed prior to weight gain and in ARC (Thaler et al., 2012). A growing body of studies has demonstrated that saturated fatty acids are the trigger for early hypothalamic inflammation and are mediated mainly by microglial cells and astrocytes (Kleinridders et al., 2009; Gupta et al., 2012; Valdearcos et al., 2014, 2017; Mendes et al., 2018). Toll-like receptor 4 (TLR4) can be activated by saturated fatty acids, inducing the activity of NF- $\kappa \mathrm{B}$ which transactivates gene expression of various proinflammatory cytokines and oxidative stress (Zhang et al., 2008; Kleinridders et al., 2009; Milanski et al., 2009). NF-кB also activates the expression of the suppressor of cytokine signaling 3 (SOCS3) which promotes negative feedback in the insulin and leptin intracellular signaling pathways, potentially linking hypothalamic inflammation with central leptin and insulin resistance (Valdearcos et al., 2015). Blocking the inflammatory process in the hypothalamus can prevent diet-induced obesity and insulin/leptin resistance (Kleinridders et al., 2009; Valdearcos et al., 2014, 2017; Mendes et al., 2018) (Figure 1B).

Neuroinflammatory damage to ARC neurons might disrupt integrated circuitry, including the communication with the downstream effector nucleus (such as PVN and LHN), and may generate a pathologic activation pattern that disturbs energy homeostasis. Targeting hypothalamic structures with DBS could thus possibly lead to weight loss and reduction in binge eating behavior if the appropriate circuits can be selectively activated or inactivated (Whiting et al., 2013).

\section{REWARD CIRCUITS, HEDONIC FEEDING, AND OBESITY}

The reward circuit structures have been implicated in motivation and desire, associative learning, and in emotions with a pleasure component related to reward. 'Liking' mechanisms include hedonic circuits that connect forebrain limbic structures such as NA and ventral pallidum (where opioid/endocannabinoid/orexin signals can amplify sensory pleasure). 'Wanting' mechanisms include larger opioid networks in NA, striatum, and amygdala that extend beyond the hedonic hotspots, as well as mesolimbic dopamine systems, and corticolimbic glutamate signals that interact with those systems (Berridge et al., 2010). Hedonic feeding is driven by sensory perception or pleasure involving reward structures and these also show a close anatomic and functional relationship with the hypothalamus and the homeostatic feeding (Rossi and Stuber, 2018). Hyperpalatable foods may be potentially "addictive" and have been compared to drugs of abuse. The cues that predict drug and food reward activate similar regions that have been implicated in reward and reward learning. The circuits involved include the mesolimbic dopamine system, which projects from the ventral tegmental area (VTA) to the NA (Stice et al., 2008). Functional MRI has shown that blood oxygen dependent signal (BOLD) in the NA is selectively increased during the perception of pleasant, emotionally arousing pictures and during mental imagery of pleasant, emotional scenes (Sabatinelli et al., 2007; Costa et al., 2010). In comparison to lean individuals, obese individuals experience greater activation in the gustatory cortex and somatosensory regions in response to anticipation and consumption of food (consummatory and anticipatory food reward) and experience a weaker activation in the striatum during food intake (Stice et al., 2008). The findings of reward responsivity in obese people can be inherited (genetic predisposition) or can result from repeated food intake or from both scenarios (Berridge et al., 2010).

On the other hand, the incidental finding of increased weight gain after discontinuation of pharmacological dopaminergic in rats suggested that hypofunctioning of dopamine circuits related to overstimulation by high palatable function could contribute to obesity (Reinholz et al., 2008). The Taq1A minor (A1) allele of the gene codifying dopamine receptors 2 and 3 (DRD2/3 gene) is associated with lower DRD2/3 density and has been found to exist in higher frequencies in obese subjects (Dang et al., 2016). In rodents, reduced DA transmission has been well documented in the striatum of obese rats (Johnson and Kenny, 2010; Rada et al., 2010). The results were in agreement with the earlier report showing lower striatal levels of D2 receptors of obese subjects in comparison to controls in 2001 (Wang et al., 2001). However, a large sample of adult subjects ( $n=130$, age between 18 and 81 years), Dang et al. (2016) show no association between o relation between DRD2/3 and BMI (range from underweight to extreme obesity) after controlling 
for age distribution. Besides that, a randomized pilot study with a dopamine agonist (cabergoline) treatment for 16 weeks did not affect significantly the weight loss, but improve the glucose tolerance (Gibson et al., 2012). Also, genetic studies in humans have suggested that striatal D2Rs for obesity etiology have been considered somewhat controversial. Experts have questioned the reward deficiency theory of "food addiction" (Benton and Young, 2016). Recently Labouesse et al. (2018) outlined a causal relationship between striatal D2Rs and obesity in mice. These authors showed that high striatal D2R during development increased the risk for obesity in the mouse and that obesogenic diets were necessary to reveal the full effects of the D2R on obesity in the mouse. This data suggested that diet was an important cofactor along with the genetic predisposition.

Although the genetic and neuroimaging studies in humans and the experimental findings in rodents suggest a complex role for the reward-related dopaminergic system in obesity, the results support the use of this circuit as a target for "stimulation" or "inhibition" by DBS.

\section{DEEP BRAIN STIMULATION}

Based partially on the notion that high-frequency stimulation could suppress extrapyramidal tremor during functional ablative neurosurgery (Hassler et al., 1960; Alberts et al., 1965, 1966), Benabid et al. (1987) moved the field toward chronic stimulation with high-frequency continuous stimulation $(130 \mathrm{~Hz})$ of the thalamic nucleus ventralis intermedius for essential tremor and for parkinsonian tremor. He showed that DBS could be applied bilaterally without pseudobulbar and cognitive side-effects, an important observation as this was the major shortcoming of bilateral lesion therapy. Collectively, these observations consolidated the concept that high-frequency DBS could provide a "functional" lesion or alternatively modulation of a relevant brain network (Grill et al., 2004). We do not completely understand the mechanism of action of DBS, however, there seem to be important associated neurophysiological, neurochemical, neurovascular, neurogenic, neurochemical (e.g., glial cells), and neuro-oscillatory changes. The application of DBS should always be focused to selectively influence a specific and even multiple brain targets to modulate a relevant neural network. It should only be applied to alleviate human suffering (Benabid et al., 1987; Miocinovic et al., 2013; Williams and Okun, 2013; Okun, 2014).

The target size and the anatomical relationship to adjacent structures should be carefully considered during surgical planning. Presently, most DBS leads contain four platinum/iridium cone shape electrodes around the lead with a $1.27 \mathrm{~mm}$ diameter and $1.5 \mathrm{~mm}$ length. The spacing between each electrode can be $1.5 \mathrm{~mm}$ or $0.5 \mathrm{~mm}$ providing, respectively, a total of $10.5 \mathrm{~mm}$ or $7.5 \mathrm{~mm}$ length distance between the deepest and the most superficial electrode borders. There are newer models with eight contacts and segmented leads with variable spacing. The DBS leads are inserted by stereotactic surgery into the targeted brain structure, and an extension wire is subcutaneously tunneled to connect the implanted pulse generator (IPG) to the DBS lead (Oluigbo et al., 2012; Okun, 2014;
Klooster et al., 2016). The IPG delivers adjustable pulses through the quadripolar electrodes and can be programmed to many settings based on voltage (or current in newer devices) amplitude, pulse width, and frequency (Hassler et al., 1960; Alberts et al., 1966; Benabid et al., 1991; Kuncel and Grill, 2004; Kringelbach et al., 2007; Brocker and Grill, 2013; Udupa and Chen, 2015). The DBS can be switched ON or OFF on demand (Oluigbo et al., 2012) in some paradigms. When the monopolar configuration is utilized a large sphere of current is generated and when bipolar is used the current is more restricted and elliptical. Newer devices may provide multiple independent current sources as well as segmented leads which can be used to steer or shape the current.

Deep brain stimulation has steadily become a safer procedure especially when an experienced multidisciplinary approach is applied. Severe adverse events are usually less than $5 \%$ in wellselected cases (Shukla et al., 2015). DBS is FDA approved in the United States for the treatment of advanced Parkinson's disease (Odekerken et al., 2013), dystonia (Meoni et al., 2017), and essential tremor (Barbe et al., 2018) and also has a humanitarian device exemption for dystonia and obsessive-compulsive disorder. DBS has been utilized in several refractory neuropsychiatric disorders including Tourette syndrome, depression (Schlaepfer et al., 2013), post-traumatic stress disorder (Koek et al., 2014), epilepsy (Salanova, 2018), obsessive-compulsive disorder (Goodman et al., 2010), pain (Farrell et al., 2018), Alzheimer's disease (Leoutsakos et al., 2018); drug addiction (Wang et al., 2018) and appetite disorders (Whiting et al., 2018).

Several observations have described a "feeling of happiness" accompanied by smile that progressed to natural laughter with DBS applied to the internal capsule/NA region for obsessivecompulsive disorder (Okun et al., 2004, 2007; Springer et al., 2006; Haq et al., 2011). Mood elevation during stimulationinduced smiles and laughter could be transient and was found to habituate with chronic NA stimulation (Springer et al., 2006; Haq et al., 2011). Rarely DBS induced mood elevation or "maniclike" symptoms in PD which were rapidly reversed with IPG reprogramming. Also, non-mood-related symptoms may also occur. Responses such as taste, smell, and smile were strongly associated with the most ventral lead positions. Similarly, physiological responses - for example, autonomic changes, increased breathing rate, sweating, nausea, cold sensation, heat sensation, fear, panic and panic episodes were significantly associated with ventral stimulation (Okun et al., 2007). Some authors showed that resistant depression treated with medial forebrain bundle DBS may improve over weeks to months (Schlaepfer et al., 2013; Fenoy et al., 2016). Perhaps most compelling was a paper by Halpern et al. (2011) which showed a delta oscillation in NA that was associated with feeding behavior in the mouse. These investigators also explored the use of neuromodulation applied to the NA in the animal and in one human case (an OCD case) as a method to modulate this "feeding" oscillation.

Taken together, clinical observations have shown that modulation can affect different limbic symptoms and this response can be exhibit variable latency. Neuromodulation for obesity treatment will need to consider the overlapping circuits 
involved with hedonic and homeostatic feeding. Selectivity of a DBS treatment to specific cells using optogenetics may also be a viable approach (Creed et al., 2015; Lüscher et al., 2015; Mastro et al., 2017).

\section{HYPOTHALAMIC DBS AS APPLIED TO OBESITY}

The hypothalamic nuclei have become targets for DBS therapy in obesity because of the known association with vegetative functions, social behavior, food behavior and control of metabolism. Human hypothalamus is a $0.7 \mathrm{~cm}^{3}$ volume and it is functionally heterogeneous and complex. It is located below the thalamus and it forms the lateral walls and floor of the third ventricle (Saper, 2004). The four hypothalamic nuclei directly involved with appetite control and food behavior are the VMH, LHA, DMH, PVN, and ARC (Lemaire et al., 2013; Barbosa et al., 2017). These are the nuclei of interest for neuromodulation.

Classical ablative studies have established VMN as the "satiety center," and LHA as the "feeding center." This dichotomy has, however, been replaced by a more complex hypothalamic neural network coupled to hormonal, metabolic and energy regulation signals (Lacan et al., 2008) as shown in Figure 1. In both rodent models and in humans obesity has been associated with hypothalamic gliosis and neuronal injury and this has been raised by some experts as a concern for future neuromodulation therapy (Thaler et al., 2012). Variations in the pattern of gliosis and also of neuronal injury distribution may impact local and distal neuroplasticity and may have implications for clinical outcome. The two nuclei require different stimulation frequencies to produce their therapeutic effects (Hamani et al., 2008; Wilent et al., 2010). Moreover, as previously described, systemic metabolic signals under fasting or non-fasting conditions (such as leptin and ghrelin) have antagonistic effects over ARC neurons (namely the POMC and AgRP) and result in the selective activation of PVN or LHA, which either favors weight loss or stimulates food behavior (Morton et al., 2014; Timper and Bruning, 2017).

As shown in Figure 1, in healthy conditions the PVN activation culminates in satiety (decreased food intake) and stimulation of energy expenditure. This nucleus is modulated by the anorexigenic POMC and orexigenic AgRP/NPY neurons from ARC nucleus. It has been suggested that to be effective for obesity, the PVN should be activated by a device directly implanted into the nucleus itself or in the ARC nucleus that projects to the PVN. A DBS neuromodulation approach of the ARC to treat obesity would preferably activate selectively the anorexigenic POMC and/or inactivate the orexigenic AgRP/NPY neurons. Because obesity is associated with complex changes in the neurophysiology of the POMC and AgRP/NPY neurons (see Figure 1), the result of ARC neuromodulation by DBS on the PVN in obese patients is tricky and an optogenetic manipulation may be a preferred approach. Also, because the PVN and ARC nuclei are relatively small, their selective modulation by DBS remains a barrier.
The DMH has been implicated in day-time feeding, in emotional responses to stress and when lesioned in male and female patients has been shown to be associated with persistent impotence and loss of libido (Meyers, 1962; Barbosa et al., 2017). Implications for DMH as a target for DBS in obesity remain to be explored.

The series and case reports about the VMH, LHA, and NA as DBS targets for obesity are discussed below and also summarized in Table 1.

\section{Ventral Medial Hypothalamus DBS}

Hamani et al. (2008) performed the first DBS trial to treat human obesity. The trial was inspired by the positive results obtained from preclinical (Halpern et al., 2011; Prinz and Stengel, 2018) and clinical studies, and it revealed that inhibition of the hypothalamus resulted in decreased food intake and weight loss (De Salles et al., 2018). Hamani et al. (2008) implanted DBS leads bilaterally in the ventral hypothalamus of one 50-year-old man with a life-long history of obesity (190.5 kg; BMI, $\left.55.1 \mathrm{~kg} / \mathrm{m}^{2}\right)$. The first stimulation parameter settings $(130 \mathrm{~Hz}, 60 \mu \mathrm{s}$, and $2.8 \mathrm{~V}$ ) did not reveal a significant effect (e.g., weight loss) during the first 6 months following surgery. Interesting, after a slight adjustment $(50 \mathrm{~Hz}, 210 \mu \mathrm{s}$, and $3-4 \mathrm{~V})$ the patient had a consequent weight loss $(12 \mathrm{~kg})$ without significant dietary changes and a reduction in food craving (Hamani et al., 2008). Because the patient reported difficulties in sleeping, the stimulation was turned off at night. The patient then began to eat at night and had increased weight (Wilent et al., 2010; Whiting et al., 2013). Wilent et al. (2010) used the same target as Hamani et al. (2008), however, in their case the stimulation $(135 \mathrm{~Hz}, 60 \mu \mathrm{s}$, and 1-7 V) was associated with an unexpected panic event, and resulted in the interruption of the treatment.

An open-label clinical trial of hypothalamic DBS for morbid obesity is currently in progress and six patients will be included (De Salles et al., 2018). The subjects are required to have a BMI greater than $40 \mathrm{~kg} / \mathrm{m}^{2}$ or to have undergone bariatric surgery with therapeutic failure, as defined by BMI $\geq 35 \mathrm{~kg} / \mathrm{m}^{2}$ (must be 5 years after the procedure). Subjects must have no obesity comorbidities such as diabetes or cardiopulmonary abnormalities. The trial aims to assess the safety, identify possible side effects, and to optimize stimulation parameters in a paradigm of continuous VMH-DBS. Additionally, the study aims to determine if continuous VMH-DBS will lead to weight loss associated with changes in body composition, basal metabolism or food intake control (De Salles et al., 2018).

\section{Lateral Hypothalamic Area (LHA) DBS}

Weight gain has been observed in patients with PD treated with the subthalamic nucleus (STN) DBS and globus pallidus internus (GPi) DBS (Novakova et al., 2007). The weight gain could be an influence of spreading electrical currents into hypothalamic pathways though this remains speculative. There are also other factors including impulse control and dyskinesia reduction which could confound the finding. Nevertheless, it is interesting that STN and GPi DBS for Parkinson's disease have both been associated with weight gain. 


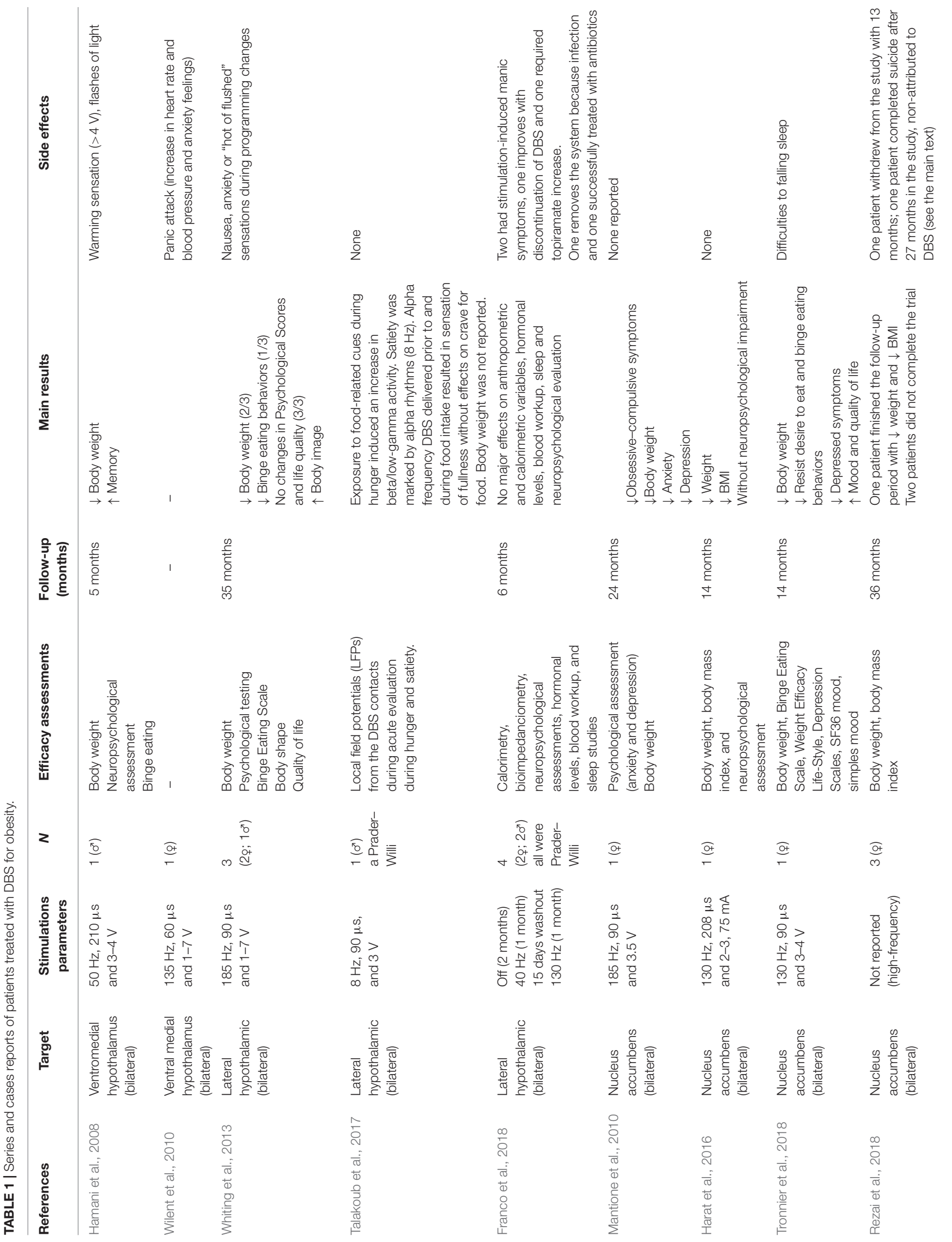


A right-side LHA hypothalamotomy lesion in two patients and bilateral in one (staged over 3 months) resulted in a transient decrease in caloric intake. This finding was compared to two patients with transient stimulation but no lesion(s) (Quaade et al., 1974).

In 2013, the first DBS treatment with electrodes implanted in the LHA was performed in three patients, (two females). All patients were previously treated with gastric bypass between 2001 and 2003 (Whiting et al., 2013). During the intraoperative microelectrode recording isolated but not discernible firing patterns were recorded. Microstimulation within the LHA produced sensations of nausea and thermal responses while more ventromedial microstimulation (presumably within the $\mathrm{VMH}$ ) resulted in an anxiety or panic response. DBS was initiated 2 months after surgery. No significant weight loss trends were observed when DBS was programmed utilizing standard settings similar to the high-frequency parameters used for movement disorder surgery. Weight loss trends were observed when monopolar DBS stimulation was applied via specific contacts found to be associated with an increase in the resting metabolic rate as measured in a respiratory chamber. After 35 months of follow-up, two patients lost weight and one had a decrease in binge eating behaviors. There were no significant neuropsychological changes across patients and no significant side effects were reported.

Hyperphagia in Prader-Willi syndrome (PWS) is an important cause of genetic obesity. Recently, Talakoub et al. (2017) recorded the local field potentials (LFPs) from the DBS contacts implanted in the LHA of a 19-year-old Prader-Willi male patient undergoing DBS for obesity. During hunger exposure to food-related cues, there was an induced increase in beta/low-gamma activity. During satiety, the recordings were marked by alpha rhythms. An alpha frequency DBS was delivered prior to and during food intake. The patient reported a sensation of fullness but had a persistent food craving. The long-term effects have yet to be reported (Talakoub et al., 2017).

Franco et al. (2018) described four patients (two males) with Prader-Willi syndrome, treated with lateral hypothalamus DBS. The cohorts age ranged from 18 to 28 and their mean (SD) baseline BMI was 39.6 (11.1). Two patients had previous bariatric surgery. All patients had psychiatric comorbidities, including skin picking, nail biting, aggressive behavior, hypersexuality, episodes of hypomania, psychosis, and impulsiveness. These behaviors were reported as adequately controlled with medications. After DBS implantation, the treatment included the following phases: titration (1-2 months), stimulation off (2 months), low-frequency DBS ( $40 \mathrm{~Hz} ; 1$ month), washout (15 days), high-frequency DBS (130 Hz; 1 month), and long-term follow-up (6 months). Six months after receiving DBS at the "best" settings, the patients had a mean $9.6 \%$ increase in weight, a 5.8\% increase in BMI, an $8.4 \%$ increase in abdominal circumference, a $4.2 \%$ increase in neck circumference, a $5.3 \%$ increase in the percentage of body fat, and a $0 \%$ change in calorimetry (as compared to baseline). The hormonal levels and results of a blood workup, sleep studies, and neuropsychological evaluations were unchanged by DBS therapy. Two patients developed manic symptoms during the titration phase, one improved with DBS programming and one required an increase in topiramate. One patient was receiving preoperative testosterone injections for hypogonadism, which infrequently resulted in priapism. One episode of priapism during the titration phase required drainage. One patient developed an infection over the connector site thought to be associated with skin picking 7 months following treatment. The family requested explantation since the device was ineffective for obesity. Another patient developed a superficial infection over IPG 1 month after the implant and this issue was successfully addressed with antibiotics.

\section{NUCLEUS ACCUMBENS DBS}

The first clinical report on NA DBS was published by Mantione et al. (2010) who treated refractory obsessive-compulsive disorder with associated nicotine dependence and also obesity (Mantione et al., 2010). In this study, a 47-year-old female patient weighed $107 \mathrm{~kg}$ with a height of $170 \mathrm{~cm}$, corresponding to a BMI of 37 was implanted with a monopolar DBS $(185 \mathrm{~Hz}, 90 \mu \mathrm{s}$, and $3.5 \mathrm{~V})$. The clinical team utilized the two deepest contacts ( 0 and 1$)$ for initial programming (accumbens region) and adjusted it using the more dorsal 1 and 2 contacts 3 weeks later, when she gradually started to improve her obsessive-compulsive symptoms. Within 5 months the Yale-Brown Obsessive-Compulsive Scale scores decreased from 38 to 2 and she reported reducing the time spent on obsessions and compulsions from $20 \mathrm{~h}$ a day to less than $1 \mathrm{~h}$ a day. The HAM-A (subclinical anxiety) and the HAM-D (subclinical depression) gradually decreased from 17 to 2 and 11 to 3 , respectively. Seven months after surgery she realized she was no longer dependent on her compulsions, but that she was still dependent on her cigarettes. She stopped smoking and stated she did not crave cigarettes and did not experience withdrawal symptoms. The 2-year follow-up evaluation showed her weight was $71 \mathrm{~kg}$, she was not smoking and she had no desire to start smoking. She scored 1 on the Yale-Brown Obsessive-Compulsive Scale, 3 on the HAM-A, and 3 on the HAM-D.

More recently in 2016, Harat et al. (2016) described a 19-yearold woman with obesity associated with a hypothalamic region that was damaged by a craniopharyngioma (neurosurgery was in 2004). She was approved for bariatric surgery but preferred DBS surgery. She was treated with bilateral NA DBS $(130 \mathrm{~Hz}$, $208 \mu \mathrm{s}$, and 2-3.75 mA). After 14 months her weight was reduced from $151.4 \mathrm{~kg}$ to $138 \mathrm{~kg}$ and her BMI from 53 to 48 . No neuropsychological or other side effects were observed as a result of the surgery (Harat et al., 2016).

Tronnier et al. (2018) reported that bilateral NA DBS $(130 \mathrm{~Hz}$, $90 \mu \mathrm{s}$, and $4 \mathrm{~V}$ ) decreased body weight, BMI and binge behavior without significant psychological impairment in a woman who was followed for 14-months. She had depression resistant to electroconvulsive therapy (ECT). Her peak weight in November 2013 was $183.6 \mathrm{~kg}$ which at a height of $167 \mathrm{~cm}$ translated to a BMI of 66. In March 2015, she underwent gastric bypass surgery after a course of behavioral therapy for her obesity and it was reported to have limited success. Because the temporary improvement of depression was less than 2 weeks and further antidepressant medication was not successful, the decision was 
made for treatment with NA DBS in November 2015. Morbid obesity of the patient was considered a secondary target of the DBS procedure. After DBS surgery, her weight loss accelerated to $2.85 \mathrm{~kg} / \mathrm{month}$. At the time of writing of this report (12/2016) her body weight has continuously decreased to $106 \mathrm{~kg}$, corresponding to a BMI of 38 . Her depressive symptoms have also been reported to be significantly reduced. Interestingly, the weight loss was accompanied with heightened feelings of "self-efficacy of ingestive behavior" that was not felt following bariatric surgery. This case raised the issue as to whether obesity associated with depression could be addressed with NA DBS.

Rezai et al. (2018) described their experience with NA DBS for obesity in three female patients followed by their multidisciplinary team. The inclusion criteria were age between 22 and 60 years, "extreme obesity" defined as BMI > 40, and patients had to fail Rou-en-Y gastric bypass surgery. Although all patients lost weight with DBS, only one participant successfully completed the 3-year trial, losing 100 pounds with a $30 \%$ BMI reduction (55.7-39.3). After 13 months in the study, one subject requested explantation. One patient died as a result of a completed suicide after 27 months into the study. All patients had significant psychiatric illness and during the trial reported major psychosocial stressors including family violence, divorce, job loss, family illness, and pet death. The study team concluded that DBS itself was not responsible for the suicide, patient withdrawal or explantation. Regarding the association between obesity and suicide, a recent systematic review and metaanalysis of 15 prospective studies showed an inverse association between obesity with suicide mortality and attempted suicide (Amiri and Behnezhad, 2018). The mechanisms related to an association between DBS and suicide are not understood but the recent Veterans Affairs study with a long term followup did not show an association with STN and GPi DBS and suicide (Weintraub et al., 2013). One confounding factor has been the early reports of suicide led most major groups to implement more careful pre-operative screening and postoperative monitoring.

Rezai et al. (2018) has suggested the following strategies to reduce suicide risk (i) Requirement of close psychiatric monitoring by clinicians trained in bariatric psychiatry and mandatory psychological therapy during the study period; (ii) Requirement of subject commitment to compliance with the study requirements and close involvement with a social support system and a study partner (a family member or close friend committed to the trial with the subject) from the subject's environment; (iii) Upfront consideration should be given to the long-term follow-up of the DBS system after the trial conclusion and should be discussed with the subjects and family support system in advance of implantation.

Finally, because of its assumed role in reward-related behavior, the ventral anterior limb of the internal capsule (vALIC) could be a potential target for obesity DBS. However, Linssen et al. (2017) reported no significant change in body weight on a group level after vALIC DBS (mean follow-up was 3.8 years, range 10 months to 8.7 years) for either obsessive-compulsive disorder $(n=30)$ or major depressive disorder $(n=16)$. The average baseline BMI in their sample of 46 patients was 28.0 (SD 7.3), with 26 (57\%) being overweight (BMI 25-30, $n=11$ ), obese (BMI 30-40, $n=12$ ), or morbidly obese (BMI $\geq 40, n=3)$.

\section{CONCLUSION AND FINAL REMARKS}

Prevention of obesity is a worldwide issue. It will required broad changes in the worldwide pattern of food ingestion and physical activity. The cost-effectiveness of innovations must be taken into account in epidemiological terms. However, in selected cases of morbid obesity, DBS, similar to gastric surgery, may in the future be refined into a therapeutic modality. Hypothalamic DBS for obesity has been shown to be reasonably safe in well-selected patients. The effectiveness has, however, not been shown to be robust or reproducible. Based on both biological plausibility and on observational studies, the NA has emerged as an alternative obesity DBS target.

Future studies should also focus on better understanding the patient characteristics most likely to benefit from obesity DBS (Tronnier et al., 2018). Specific DBS targets may be optimal for specific clinical phenotypes. The therapy could thus become more personalized (Famm et al., 2013).

The identification of electrical control signals may provide an opportunity for closed-loop adaptive DBS systems to address obesity (Carron et al., 2013; Kuhn and Volkmann, 2017). Metabolic and hormonal sensors such as glycemic levels (Christiansen et al., 2018), leptin and ghrelin levels are candidate control signals for DBS.

Newer approaches for obesity DBS should be explored. Focused excitation or alternatively inhibition of regions of the hypothalamus may provide better outcomes compared to nonselective DBS. Utilization of the delta oscillation (Halpern et al., 2011) or other physiological markers from one or multiple regions in the obesity network is a promising approach.

Finally, it will be important to implement expert multidisciplinary screening teams as well as post-operative monitoring to lessen the occurrence of neuropsychiatric adverse events.

\section{AUTHOR CONTRIBUTIONS}

DF, JG, HM, TE, RZ, AL, and RW wrote the manuscript. TE, JG, and DF elaborated the tables and figures. AL, JG, $\mathrm{MO}$, and RW participated in the conception of the idea and revised the manuscript.

\section{FUNDING}

$\mathrm{AL}$ and RW are Research Fellows from CNPq (Brazilian Council for Scientific and Technologic Development, Brazil). AL and RW were supported by PRONEX Program of FAPESC/CNPq (NENASC Project). DF, HM, and TE are supported by scholarships from CAPES. JG was supported by $\mathrm{CNPq}$ (401842/2018-5). RZ is supported by Fondecyt n 11140757. MO serves as a consultant for the National Parkinson Foundation, and has received research grants from NIH, NPF, the Michael J. Fox 
Foundation, the Parkinson Alliance, Smallwood Foundation, the Bachmann-Strauss Foundation, the Tourette Syndrome Association, and the UF Foundation. MO's DBS research is supported by: R01 NR014852 and R01NS096008. MO has previously received honoraria, but in the past $>60$ months has received no support from industry. MO has received royalties for publications with Demos, Manson, Amazon, Smashwords, Books4Patients, and Cambridge (movement disorders books). $\mathrm{MO}$ is an associate editor for New England Journal of Medicine

\section{REFERENCES}

Al Massadi, O., Lopez, M., Tschop, M., Dieguez, C., and Nogueiras, R. (2017). Current understanding of the hypothalamic ghrelin pathways inducing appetite and adiposity. Trends Neurosci. 40, 167-180. doi: 10.1016/j.tins.2016.12.003

Alberts, W. W., Feinstein, B., Levin, G., and Wright, E. W. Jr. (1966). Electrical stimulation of therapeutic targets in waking dyskinetic patients. Electroencephalogr. Clin. Neurophysiol. 20, 559-566. doi: 10.1016/00134694(66)90020-4

Alberts, W. W., Feinstein, B., Levin, G., Wright, E. W. Jr., Darland, M. G., and Scott, E. L. (1965). Stereotaxic surgery for parkinsonism. Clinical results and stimulation thresholds. J. Neurosurg. 23, 174-183. doi: 10.3171/jns.1965.23.2. 0174

Amiri, S., and Behnezhad, S. (2018). Body mass index and risk of suicide: a systematic review and meta-analysis. J. Affect. Disord. 238, 615-625. doi: 10.1016/j.jad.2018.05.028

Barbe, M. T., Reker, P., Hamacher, S., Franklin, J., Kraus, D., Dembek, T. A., et al. (2018). DBS of the PSA and the VIM in essential tremor: a randomized, double-blind, crossover trial. Neurology 91, e543-e550. doi: 10.1212/WNL. 0000000000005956

Barbosa, D. A. N., De Oliveira-Souza, R., Monte Santo, F., De Oliveira Faria, A. C., Gorgulho, A. A., and De Salles, A. A. F. (2017). The hypothalamus at the crossroads of psychopathology and neurosurgery. Neurosurg. Focus 43:E15. doi: 10.3171/2017.6.FOCUS17256

Belgardt, B. F., Husch, A., Rother, E., Ernst, M. B., Wunderlich, F. T., Hampel, B., et al. (2008). PDK1 deficiency in POMC-expressing cells reveals FOXO1dependent and -independent pathways in control of energy homeostasis and stress response. Cell Metab. 7, 291-301. doi: 10.1016/j.cmet.2008.01.006

Benabid, A. L., Pollak, P., Gervason, C., Hoffmann, D., Gao, D. M., Hommel, M., et al. (1991). Long-term suppression of tremor by chronic stimulation of the ventral intermediate thalamic nucleus. Lancet 337, 403-406. doi: 10.1016/01406736(91)91175- T

Benabid, A. L., Pollak, P., Louveau, A., Henry, S., and De Rougemont, J. (1987). Combined (thalamotomy and stimulation) stereotactic surgery of the VIM thalamic nucleus for bilateral Parkinson disease. Appl. Neurophysiol. 50, 344-346. doi: 10.1159/000100803

Benton, D., and Young, H. A. (2016). A meta-analysis of the relationship between brain dopamine receptors and obesity: a matter of changes in behavior rather than food addiction? Int. J. Obes. 40(Suppl. 1), S12-S21. doi: 10.1038/ijo.2016.9

Berridge, K. C., Ho, C. Y., Richard, J. M., and Difeliceantonio, A. G. (2010). The tempted brain eats: pleasure and desire circuits in obesity and eating disorders. Brain Res. 1350, 43-64. doi: 10.1016/j.brainres.2010.04.003

Brocker, D. T., and Grill, W. M. (2013). Principles of electrical stimulation of neural tissue. Handb. Clin. Neurol. 116, 3-18. doi: 10.1016/B978-0-444-534972.00001-2

Carron, R., Chaillet, A., Filipchuk, A., Pasillas-Lepine, W., and Hammond, C. (2013). Closing the loop of deep brain stimulation. Front. Syst. Neurosci. 7:112. doi: 10.3389/fnsys.2013.00112

Cavadas, C., Aveleira, C. A., Souza, G. F., and Velloso, L. A. (2016). The pathophysiology of defective proteostasis in the hypothalamus - from obesity to ageing. Nat. Rev. Endocrinol. 12, 723-733. doi: 10.1038/nrendo. 2016.107

Cheung, C. C., Clifton, D. K., and Steiner, R. A. (1997). Proopiomelanocortin neurons are direct targets for leptin in the hypothalamus. Endocrinology 138, 4489-4492. doi: 10.1210/endo.138.10.5570
Journal Watch Neurology. MO has participated in CME and educational activities on movement disorders (in the last 36) months sponsored by PeerView, Prime, QuantiaMD, WebMD, Medicus, MedNet, Henry Stewart, and by Vanderbilt University. The institution and not MO receives grants from Medtronic, Abbvie, Allergan, and ANS/St. Jude, and the PI has no financial interest in these grants. MO has participated as a site PI and/or co-PI for several NIH, foundation, and industry sponsored trials over the years but has not received honoraria.

Christiansen, M. P., Klaff, L. J., Brazg, R., Chang, A. R., Levy, C. J., Lam, D., et al. (2018). A prospective multicenter evaluation of the accuracy of a novel implanted continuous glucose sensor: PRECISE II. Diabetes Technol. Ther. 20, 197-206. doi: 10.1089/dia.2017.0142

Costa, V. D., Lang, P. J., Sabatinelli, D., Versace, F., and Bradley, M. M. (2010). Emotional imagery: assessing pleasure and arousal in the brain's reward circuitry. Hum. Brain Mapp. 31, 1446-1457. doi: 10.1002/hbm.20948

Creed, M., Pascoli, V. J., and Lüscher, C. (2015). Addiction therapy. Refining deep brain stimulation to emulate optogenetic treatment of synaptic pathology. Science 347, 659-664. doi: 10.1126/science. 1260776

Dang, L. C., Samanez-Larkin, G. R., Castrellon, J. J., Perkins, S. F., Cowan, R. L., and Zald, D. H. (2016). Associations between dopamine D2 receptor availability and BMI depend on age. Neuroimage 138, 176-183. doi: 10.1016/j.neuroimage. 2016.05.044

De Salles, A. A. F., Barbosa, D. A. N., Fernandes, F., Abucham, J., Nazato, D. M., Oliveira, J. D., et al. (2018). An open-label clinical trial of hypothalamic deep brain stimulation for human morbid obesity: BLESS study protocol. Neurosurgery 83, 800-809. doi: 10.1093/neuros/nyy024

De Souza, C. T., Araujo, E. P., Bordin, S., Ashimine, R., Zollner, R. L., Boschero, A. C., et al. (2005). Consumption of a fat-rich diet activates a proinflammatory response and induces insulin resistance in the hypothalamus. Endocrinology 146, 4192-4199. doi: 10.1210/en.2004-1520

Famm, K., Litt, B., Tracey, K. J., Boyden, E. S., and Slaoui, M. (2013). Drug discovery: a jump-start for electroceuticals. Nature 496, 159-161. doi: 10.1038/ 496159a

Farrell, S. M., Green, A., and Aziz, T. (2018). The current state of deep brain stimulation for chronic pain and its context in other forms of neuromodulation. Brain Sci. 8:E158. doi: 10.3390/brainsci8080158

Fenoy, A. J., Schulz, P., Selvaraj, S., Burrows, C., Spiker, D., Cao, B., et al. (2016). Deep brain stimulation of the medial forebrain bundle: distinctive responses in resistant depression. J. Affect. Disord. 203, 143-151. doi: 10.1016/j.jad.2016. 05.064

Franco, R. R., Fonoff, E. T., Alvarenga, P. G., Alho, E. J. L., Lopes, A. C., Hoexter, M. Q., et al. (2018). Assessment of safety and outcome of lateral hypothalamic deep brain stimulation for obesity in a small series of patients with prader-willi syndrome. JAMA Netw. Open 1:e185275. doi: 10.1001/jamanetworkopen.2018. 5275

Gaspar, J. M., Baptista, F. I., Macedo, M. P., and Ambrosio, A. F. (2016). Inside the diabetic brain: role of different players involved in cognitive decline. ACS Chem. Neurosci. 7, 131-142. doi: 10.1021/acschemneuro. $5 \mathrm{~b} 00240$

Gibson, C. D., Karmally, W., Mcmahon, D. J., Wardlaw, S. L., and Korner, J. (2012). Randomized pilot study of cabergoline, a dopamine receptor agonist: effects on body weight and glucose tolerance in obese adults. Diabetes Obes. Metab. 14, 335-340. doi: 10.1111/j.1463-1326.2011.01534.x

Gonzalez-Muniesa, P., Martinez-Gonzalez, M. A., Hu, F. B., Despres, J. P., Matsuzawa, Y., Loos, R. J. F., et al. (2017). Obesity. Nat. Rev. Dis. Primers 3:17034. doi: 10.1038/nrdp.2017.34

Goodman, W. K., Foote, K. D., Greenberg, B. D., Ricciuti, N., Bauer, R., Ward, H., et al. (2010). Deep brain stimulation for intractable obsessive compulsive disorder: pilot study using a blinded, staggered-onset design. Biol. Psychiatry 67, 535-542. doi: 10.1016/j.biopsych.2009.11.028

Grill, W. M., Snyder, A. N., and Miocinovic, S. (2004). Deep brain stimulation creates an informational lesion of the stimulated nucleus. Neuroreport 15, 1137-1140. doi: 10.1097/00001756-200405190-00011 
Gupta, S., Knight, A. G., Gupta, S., Keller, J. N., and Bruce-Keller, A. J. (2012). Saturated long-chain fatty acids activate inflammatory signaling in astrocytes. J. Neurochem. 120, 1060-1071. doi: 10.1111/j.1471-4159.2012.07660.x

Hahn, T. M., Breininger, J. F., Baskin, D. G., and Schwartz, M. W. (1998). Coexpression of Agrp and NPY in fasting-activated hypothalamic neurons. Nat. Neurosci. 1, 271-272. doi: 10.1038/1082

Hakansson, M. L., and Meister, B. (1998). Transcription factor STAT3 in leptin target neurons of the rat hypothalamus. Neuroendocrinology 68, 420-427. doi: $10.1159 / 000054392$

Halpern, C. H., Torres, N., Hurtig, H. I., Wolf, J. A., Stephen, J., Oh, M. Y., et al. (2011). Expanding applications of deep brain stimulation: a potential therapeutic role in obesity and addiction management. Acta Neurochir. 153, 2293-2306. doi: 10.1007/s00701-011-1166-3

Hamani, C., Mcandrews, M. P., Cohn, M., Oh, M., Zumsteg, D., Shapiro, C. M., et al. (2008). Memory enhancement induced by hypothalamic/fornix deep brain stimulation. Ann. Neurol. 63, 119-123. doi: 10.1002/ana.21295

Haq, I. U., Foote, K. D., Goodman, W. G., Wu, S. S., Sudhyadhom, A., Ricciuti, N., et al. (2011). Smile and laughter induction and intraoperative predictors of response to deep brain stimulation for obsessive-compulsive disorder. Neuroimage 54(Suppl. 1), S247-S255. doi: 10.1016/j.neuroimage.2010.03.009

Harat, M., Rudas, M., Zielinski, P., Birska, J., and Sokal, P. (2016). Nucleus accumbens stimulation in pathological obesity. Neurol. Neurochir. Pol. 50, 207-210. doi: 10.1016/j.pjnns.2016.01.014

Hassler, R., Riechert, T., Mundinger, F., Umbach, W., and Ganglberger, J. A. (1960). Physiological observations in stereotaxic operations in extrapyramidal motor disturbances. Brain 83, 337-350. doi: 10.1093/brain/83.2.337

Hetherington, A. W., and Ranson, S. W. (1940). Hypothalamic lesions and adiposity in the rat. Anat. Rec. Banner 78, 149-172. doi: 10.1002/ar.1090780203

Horstmann, A. (2017). It wasn't me; it was my brain - Obesity-associated characteristics of brain circuits governing decision-making. Physiol. Behav. 176, 125-133. doi: 10.1016/j.physbeh.2017.04.001

Hotamisligil, G. S. (2017). Inflammation, metaflammation and immunometabolic disorders. Nature 542, 177-185. doi: 10.1038/nature21363

Ivezaj, V., White, M. A., and Grilo, C. M. (2016). Examining binge-eating disorder and food addiction in adults with overweight and obesity. Obesity 24, 20642069. doi: 10.1002/oby.21607

Johnson, P. M., and Kenny, P. J. (2010). Dopamine D2 receptors in addictionlike reward dysfunction and compulsive eating in obese rats. Nat. Neurosci. 13, 635-641. doi: 10.1038/nn.2519

Kamegai, J., Tamura, H., Shimizu, T., Ishii, S., Sugihara, H., and Wakabayashi, I. (2000). Central effect of ghrelin, an endogenous growth hormone secretagogue, on hypothalamic peptide gene expression. Endocrinology 141, 4797-4800. doi: 10.1210/endo.141.12.7920

Kleinridders, A., Schenten, D., Konner, A. C., Belgardt, B. F., Mauer, J., Okamura, T., et al. (2009). MyD88 signaling in the CNS is required for development of fatty acid-induced leptin resistance and diet-induced obesity. Cell Metab. 10, 249-259. doi: 10.1016/j.cmet.2009.08.013

Klooster, D. C., De Louw, A. J., Aldenkamp, A. P., Besseling, R. M., Mestrom, R. M., Carrette, S., et al. (2016). Technical aspects of neurostimulation: focus on equipment, electric field modeling, and stimulation protocols. Neurosci. Biobehav. Rev. 65, 113-141. doi: 10.1016/j.neubiorev.2016.02.016

Koek, R. J., Langevin, J. P., Krahl, S. E., Kosoyan, H. J., Schwartz, H. N., Chen, J. W., et al. (2014). Deep brain stimulation of the basolateral amygdala for treatment-refractory combat post-traumatic stress disorder (PTSD): study protocol for a pilot randomized controlled trial with blinded, staggered onset of stimulation. Trials 15:356. doi: 10.1186/1745-621515-356

Kringelbach, M. L., Jenkinson, N., Owen, S. L., and Aziz, T. Z. (2007). Translational principles of deep brain stimulation. Nat. Rev. Neurosci. 8, 623-635. doi: 10. 1038/nrn2196

Kuhn, A. A., and Volkmann, J. (2017). Innovations in deep brain stimulation methodology. Mov. Disord. 32, 11-19. doi: 10.1002/mds.26703

Kuncel, A. M., and Grill, W. M. (2004). Selection of stimulus parameters for deep brain stimulation. Clin. Neurophysiol. 115, 2431-2441. doi: 10.1016/j.clinph. 2004.05.031

Labouesse, M. A., Sartori, A. M., Weinmann, O., Simpson, E. H., Kellendonk, C., and Weber-Stadlbauer, U. (2018). Striatal dopamine 2 receptor upregulation during development predisposes to diet-induced obesity by reducing energy output in mice. Proc. Natl. Acad. Sci. U.S.A. 115, 10493-10498. doi: 10.1073/ pnas. 1800171115

Lacan, G., De Salles, A. A., Gorgulho, A. A., Krahl, S. E., Frighetto, L., Behnke, E. J., et al. (2008). Modulation of food intake following deep brain stimulation of the ventromedial hypothalamus in the vervet monkey. Laboratory investigation. J. Neurosurg. 108, 336-342. doi: 10.3171/JNS/2008/108/2/0336

Lee, S., Lee, J., Kang, G. M., and Kim, M. S. (2018). Leptin directly regulate intrinsic neuronal excitability in hypothalamic POMC neurons but not in AgRP neurons in food restricted mice. Neurosci. Lett. 681, 105-109. doi: 10.1016/j.neulet.2018. 05.041

Lemaire, J. J., Nezzar, H., Sakka, L., Boirie, Y., Fontaine, D., Coste, A., et al. (2013). Maps of the adult human hypothalamus. Surg. Neurol. Int. 4, S156-S163. doi: 10.4103/2152-7806.110667

Leoutsakos, J. S., Yan, H., Anderson, W. S., Asaad, W. F., Baltuch, G., Burke, A., et al. (2018). Deep brain stimulation targeting the fornix for mild alzheimer dementia (the ADvance Trial): a two year follow-up including results of delayed activation. J. Alzheimers Dis. 64, 597-606. doi: 10.3233/JAD-180121

Linssen, R. S. N., Oudijn, M. S., Mantione, M., Van Den Munckhof, P., Denys, D., and Schuurman, P. R. (2017). Body weight changes after deep brain stimulation for obsessive-compulsive disorder or depression. Stereotact. Funct. Neurosurg. 95, 348-351. doi: 10.1159/000480665

Liotta, A. S., Loudes, C., Mckelvy, J. F., and Krieger, D. T. (1980). Biosynthesis of precursor corticotropin/endorphin-, corticotropin-, alpha-melanotropin-, beta-lipotropin-, and beta-endorphin-like material by cultured neonatal rat hypothalamic neurons. Proc. Natl. Acad. Sci. U.S.A. 77, 1880-1884. doi: 10. 1073/pnas.77.4.1880

Luquet, S., Perez, F. A., Hnasko, T. S., and Palmiter, R. D. (2005). NPY/AgRP neurons are essential for feeding in adult mice but can be ablated in neonates. Science 310, 683-685. doi: 10.1126/science.1115524

Lüscher, C., Pascoli, V., and Creed, M. (2015). Optogenetic dissection of neural circuitry: from synaptic causalities to blue prints for novel treatments of behavioral diseases. Curr. Opin. Neurobiol. 35, 95-100. doi: 10.1016/j.conb. 2015.07.005

Mantione, M., Van De Brink, W., Schuurman, P. R., and Denys, D. (2010). Smoking cessation and weight loss after chronic deep brain stimulation of the nucleus accumbens: therapeutic and research implications: case report. Neurosurgery 66:E218; discussion E218. doi: 10.1227/01.NEU.0000360570.40339.64

Mastro, K. J., Zitelli, K. T., Willard, A. M., Leblanc, K. H., Kravitz, A. V., and Gittis, A. H. (2017). Cell-specific pallidal intervention induces long-lasting motor recovery in dopamine-depleted mice. Nat. Neurosci. 20, 815-823. doi: $10.1038 / \mathrm{nn} .4559$

McClelland, J., Bozhilova, N., Campbell, I., and Schmidt, U. (2013). A systematic review of the effects of neuromodulation on eating and body weight: evidence from human and animal studies. Eur. Eat. Disord. Rev. 21, 436-455. doi: 10. 1002/erv.2256

Mendes, N. F., Gaspar, J. M., Lima-Júnior, J. C., Donato, J. Jr., Velloso, L. A., and Araújo, E. P. (2018). TGF-betal down-regulation in the mediobasal hypothalamus attenuates hypothalamic inflammation and protects against diet-induced obesity. Metabolism 85, 171-182. doi: 10.1016/j.metabol.2018. 04.005

Meoni, S., Fraix, V., Castrioto, A., Benabid, A. L., Seigneuret, E., Vercueil, L., et al. (2017). Pallidal deep brain stimulation for dystonia: a long term study. J. Neurol. Neurosurg. Psychiatry 88, 960-967. doi: 10.1136/jnnp-2016315504

Meyers, R. (1962). Three cases of myoclonus alleviated by bilateral ansotomy, with a note on postoperative alibido and impotence. J. Neurosurg. 19, 71-81. doi: 10.3171/jns.1962.19.1.0071

Milanski, M., Degasperi, G., Coope, A., Morari, J., Denis, R., Cintra, D. E., et al. (2009). Saturated fatty acids produce an inflammatory response predominantly through the activation of TLR4 signaling in hypothalamus: implications for the pathogenesis of obesity. J. Neurosci. 29, 359-370. doi: 10.1523/JNEUROSCI. 2760-08.2009

Miocinovic, S., Somayajula, S., Chitnis, S., and Vitek, J. L. (2013). History, applications, and mechanisms of deep brain stimulation. JAMA Neurol. 70, 163-171. doi: 10.1001/2013.jamaneurol.45

Morton, G. J., Meek, T. H., and Schwartz, M. W. (2014). Neurobiology of food intake in health and disease. Nat. Rev. Neurosci. 15, 367-378. doi: 10.1038/ nrn3745 
Mountjoy, K. G. (2015). Pro-opiomelanocortin (POMC) neurones, POMC-derived peptides, melanocortin receptors and obesity: how understanding of this system has changed over the last decade. J. Neuroendocrinol. 27, 406-418. doi: 10.1111/ jne. 12285

Novakova, L., Ruzicka, E., Jech, R., Serranova, T., Dusek, P., and Urgosik, D. (2007). Increase in body weight is a non-motor side effect of deep brain stimulation of the subthalamic nucleus in Parkinson's disease. Neuro Endocrinol. Lett. 28, 21-25.

Odekerken, V. J., Van Laar, T., Staal, M. J., Mosch, A., Hoffmann, C. F., Nijssen, P. C., et al. (2013). Subthalamic nucleus versus globus pallidus bilateral deep brain stimulation for advanced Parkinson's disease (NSTAPS study): a randomised controlled trial. Lancet Neurol. 12, 37-44. doi: 10.1016/S14744422(12)70264-8

Okun, M. S. (2014). Deep-brain stimulation-entering the era of human neural-network modulation. N. Engl. J. Med. 371, 1369-1373. doi: 10.1056/ NEJMp1408779

Okun, M. S., Bowers, D., Springer, U., Shapira, N. A., Malone, D., Rezai, A. R., et al. (2004). What's in a "smile?" Intra-operative observations of contralateral smiles induced by deep brain stimulation. Neurocase 10, 271-279. doi: 10.1080/ 13554790490507632

Okun, M. S., Mann, G., Foote, K. D., Shapira, N. A., Bowers, D., Springer, U., et al. (2007). Deep brain stimulation in the internal capsule and nucleus accumbens region: responses observed during active and sham programming. J. Neurol. Neurosurg. Psychiatry 78, 310-314. doi: 10.1136/jnnp.2006.095315

Oluigbo, C. O., Salma, A., and Rezai, A. R. (2012). Deep brain stimulation for neurological disorders. IEEE Rev. Biomed. Eng. 5, 88-99. doi: 10.1109/RBME. 2012.2197745

Prinz, P., and Stengel, A. (2018). Deep brain stimulation-possible treatment strategy for pathologically altered body weight? Brain Sci. 8:E19. doi: 10.3390/ brainsci8010019

Quaade, F., Vaernet, K., and Larsson, S. (1974). Stereotaxic stimulation and electrocoagulation of the lateral hypothalamus in obese humans. Acta Neurochir. 30, 111-117. doi: 10.1007/BF01405759

Rada, P., Bocarsly, M. E., Barson, J. R., Hoebel, B. G., and Leibowitz, S. F. (2010). Reduced accumbens dopamine in Sprague-Dawley rats prone to overeating a fat-rich diet. Physiol. Behav. 101, 394-400. doi: 10.1016/j.physbeh.2010.07.005

Rajan, T. M., and Menon, V. (2017). Psychiatric disorders and obesity: a review of association studies. J. Postgrad. Med. 63, 182-190. doi: 10.4103/jpgm.JPGM_ $712 \_16$

Reinholz, J., Skopp, O., Breitenstein, C., Bohr, I., Winterhoff, H., and Knecht, S. (2008). Compensatory weight gain due to dopaminergic hypofunction: new evidence and own incidental observations. Nutr. Metab. 5:35. doi: 10.1186/ 1743-7075-5-35

Remor, A. P., Da Silva, R. A., De Matos, F. J., Glaser, V., De Paula Martins, R., Ghisoni, K., et al. (2018). Chronic metabolic derangement-induced cognitive deficits and neurotoxicity are associated with REST inactivation. Mol. Neurobiol. 56, 1539-1557. doi: 10.1007/s12035-018-1175-9

Rezai, A. R., Krishna, V., Bogner, J., Kramer, D., Needleman, B., Emerson, A. M., et al. (2018). Letter: feasibility of nucleus accumbens deep brain stimulation for morbid, treatment-refractory obesity. Neurosurgery 82, E136-E137. doi: 10.1093/neuros/nyx630

Rossi, M. A., and Stuber, G. D. (2018). Overlapping brain circuits for homeostatic and hedonic feeding. Cell Metab. 27, 42-56. doi: 10.1016/j.cmet.2017.09.021

Sabatinelli, D., Bradley, M. M., Lang, P. J., Costa, V. D., and Versace, F. (2007). Pleasure rather than salience activates human nucleus accumbens and medial prefrontal cortex. J. Neurophysiol. 98, 1374-1379. doi: 10.1152/jn.00230.2007

Salanova, V. (2018). Deep brain stimulation for epilepsy. Epilepsy Behav. 88S, 21-24. doi: 10.1016/j.yebeh.2018.06.041

Saper, C. B. (2004). "Hypothalamus," in The Human Nervous System, 2nd Edn, eds G. Paxinos and J. Mai (Philadelphia, PA: Elsevier).

Schlaepfer, T. E., Bewernick, B. H., Kayser, S., Madler, B., and Coenen, V. A. (2013). Rapid effects of deep brain stimulation for treatment-resistant major depression. Biol. Psychiatry 73, 1204-1212. doi: 10.1016/j.biopsych.2013.01.034

Shukla, A. W., Bona, A. R., and Walz, R. (2015). “Troubleshooting in DBS," in Deep Brain Stimulation, ed. R. Mehanna (New York, NY: Nova Science Publishers), 213-261.

Sohn, J. W. (2015). Network of hypothalamic neurons that control appetite. $B M B$ Rep. 48, 229-233. doi: 10.5483/BMBRep.2015.48.4.272
Springer, U. S., Bowers, D., Goodman, W. K., Shapira, N. A., Foote, K. D., and Okun, M. S. (2006). Long-term habituation of the smile response with deep brain stimulation. Neurocase 12, 191-196. doi: 10.1080/13554790600646995

Stice, E., Figlewicz, D. P., Gosnell, B. A., Levine, A. S., and Pratt, W. E. (2013). The contribution of brain reward circuits to the obesity epidemic. Neurosci. Biobehav. Rev. 37, 2047-2058. doi: 10.1016/j.neubiorev.2012.12.001

Stice, E., Spoor, S., Bohon, C., Veldhuizen, M. G., and Small, D. M. (2008). Relation of reward from food intake and anticipated food intake to obesity: a functional magnetic resonance imaging study. J. Abnorm. Psychol. 117, 924-935. doi: 10.1037/a0013600

Talakoub, O., Paiva, R. R., Milosevic, M., Hoexter, M. Q., Franco, R., Alho, E., et al. (2017). Lateral hypothalamic activity indicates hunger and satiety states in humans. Ann. Clin. Transl. Neurol. 4, 897-901. doi: 10.1002/acn3.466

Thaler, J. P., Yi, C. X., Schur, E. A., Guyenet, S. J., Hwang, B. H., Dietrich, M. O., et al. (2012). Obesity is associated with hypothalamic injury in rodents and humans. J. Clin. Invest. 122, 153-162. doi: 10.1172/JCI59660

Timper, K., and Bruning, J. C. (2017). Hypothalamic circuits regulating appetite and energy homeostasis: pathways to obesity. Dis. Model. Mech. 10, 679-689. doi: $10.1242 / \mathrm{dmm} .026609$

Tronnier, V. M., Rasche, D., Thorns, V., Alvarez-Fischer, D., Munte, T. F., and Zurowski, B. (2018). Massive weight loss following deep brain stimulation of the nucleus accumbens in a depressed woman. Neurocase 24, 49-53. doi: $10.1080 / 13554794.2018 .1431678$

Udupa, K., and Chen, R. (2015). The mechanisms of action of deep brain stimulation and ideas for the future development. Prog. Neurobiol. 133, 27-49. doi: 10.1016/j.pneurobio.2015.08.001

Valdearcos, M., Douglass, J. D., Robblee, M. M., Dorfman, M. D., Stifler, D. R., Bennett, M. L., et al. (2017). Microglial inflammatory signaling orchestrates the hypothalamic immune response to dietary excess and mediates obesity susceptibility. Cell Metab. 26, 185-197.e3. doi: 10.1016/j.cmet.2017.05.015

Valdearcos, M., Robblee, M. M., Benjamin, D. I., Nomura, D. K., Xu, A. W., and Koliwad, S. K. (2014). Microglia dictate the impact of saturated fat consumption on hypothalamic inflammation and neuronal function. Cell Rep. 9, 2124-2138. doi: 10.1016/j.celrep.2014.11.018

Valdearcos, M., Xu, A. W., and Koliwad, S. K. (2015). Hypothalamic inflammation in the control of metabolic function. Annu. Rev. Physiol. 77, 131-160. doi: 10.1146/annurev-physiol-021014-071656

Val-Laillet, D., Aarts, E., Weber, B., Ferrari, M., Quaresima, V., Stoeckel, L. E., et al. (2015). Neuroimaging and neuromodulation approaches to study eating behavior and prevent and treat eating disorders and obesity. Neuroimage Clin. 8, 1-31. doi: 10.1016/j.nicl.2015.03.016

Wang, G. J., Volkow, N. D., Logan, J., Pappas, N. R., Wong, C. T., Zhu, W., et al. (2001). Brain dopamine and obesity. Lancet 357, 354-357. doi: 10.1016/S01406736(00)03643-6

Wang, T. R., Moosa, S., Dallapiazza, R. F., Elias, W. J., and Lynch, W. J. (2018). Deep brain stimulation for the treatment of drug addiction. Neurosurg. Focus 45:E11. doi: 10.3171/2018.5.FOCUS18163

Wang, X., Ge, A., Cheng, M., Guo, F., Zhao, M., Zhou, X., et al. (2012). Increased hypothalamic inflammation associated with the susceptibility to obesity in rats exposed to high-fat diet. Exp. Diabetes Res. 2012:847246. doi: 10.1155/2012/ 847246

Wardlaw, S. L. (2011). Hypothalamic proopiomelanocortin processing and the regulation of energy balance. Eur. J. Pharmacol. 660, 213-219. doi: 10.1016/j. ejphar.2010.10.107

Weintraub, D., Duda, J. E., Carlson, K., Luo, P., Sagher, O., Stern, M., et al. (2013). Suicide ideation and behaviours after STN and GPi DBS surgery for Parkinson's disease: results from a randomised, controlled trial. J. Neurol. Neurosurg. Psychiatry 84, 1113-1118. doi: 10.1136/jnnp-2012-304396

Whiting, A. C., Oh, M. Y., and Whiting, D. M. (2018). Deep brain stimulation for appetite disorders: a review. Neurosurg. Focus 45:E9. doi: 10.3171/2018.4. FOCUS18141

Whiting, D. M., Tomycz, N. D., Bailes, J., De Jonge, L., Lecoultre, V., Wilent, B., et al. (2013). Lateral hypothalamic area deep brain stimulation for refractory obesity: a pilot study with preliminary data on safety, body weight, and energy metabolism. J. Neurosurg. 119, 56-63. doi: 10.3171/2013.2.JNS12903

Wilent, W. B., Oh, M. Y., Buetefisch, C. M., Bailes, J. E., Cantella, D., Angle, C., et al. (2010). Induction of panic attack by stimulation of the ventromedial hypothalamus. J. Neurosurg. 112, 1295-1298. doi: 10.3171/2009.9.JNS09577 
Williams, N. R., and Okun, M. S. (2013). Deep brain stimulation (DBS) at the interface of neurology and psychiatry. J. Clin. Invest. 123, 4546-4556. doi: $10.1172 /$ JCI68341

Wu, Q., Lemus, M. B., Stark, R., Bayliss, J. A., Reichenbach, A., Lockie, S. H., et al. (2014). The temporal pattern of cfos activation in hypothalamic, cortical, and brainstem nuclei in response to fasting and refeeding in male mice. Endocrinology 155, 840-853. doi: 10.1210/en.20131831

Zhang, X., and van den Pol, A. N. (2016). Hypothalamic arcuate nucleus tyrosine hydroxylase neurons play orexigenic role in energy homeostasis. Nat. Neurosci. 19, 1341-1347. doi: 10.1038/nn.4372

Zhang, X., Zhang, G., Zhang, H., Karin, M., Bai, H., and Cai, D. (2008). Hypothalamic IKKbeta/NF-kappaB and ER stress link overnutrition to energy imbalance and obesity. Cell 135, 61-73. doi: 10.1016/j.cell.2008. 07.043
Zhang, Y., Proenca, R., Maffei, M., Barone, M., Leopold, L., and Friedman, J. M. (1994). Positional cloning of the mouse obese gene and its human homologue. Nature 372, 425-432. doi: 10.1038/372425a0

Conflict of Interest Statement: The authors declare that the research was conducted in the absence of any commercial or financial relationships that could be construed as a potential conflict of interest.

Copyright $\odot 2019$ Formolo, Gaspar, Melo, Eichwald, Zepeda, Latini, Okun and Walz. This is an open-access article distributed under the terms of the Creative Commons Attribution License (CC BY). The use, distribution or reproduction in other forums is permitted, provided the original author(s) and the copyright owner(s) are credited and that the original publication in this journal is cited, in accordance with accepted academic practice. No use, distribution or reproduction is permitted which does not comply with these terms. 